\title{
Life cycle assessment comparing the treatment of surplus activated sludge in a sludge treatment reed bed system with mechanical treatment on centrifuge
}

\author{
Larsen, Julie Dam; Hoeve, Marieke ten; Nielsen, Steen; Scheutz, Charlotte
}

Published in:

Journal of Cleaner Production

Link to article, DOI:

10.1016/j.jclepro.2018.02.193

Publication date:

2018

Document Version

Peer reviewed version

Link back to DTU Orbit

Citation (APA):

Larsen, J. D., Hoeve, M. T., Nielsen, S., \& Scheutz, C. (2018). Life cycle assessment comparing the treatment of surplus activated sludge in a sludge treatment reed bed system with mechanical treatment on centrifuge. Journal of Cleaner Production, 185, 148-156. https://doi.org/10.1016/j.jclepro.2018.02.193

\section{General rights}

Copyright and moral rights for the publications made accessible in the public portal are retained by the authors and/or other copyright owners and it is a condition of accessing publications that users recognise and abide by the legal requirements associated with these rights.

- Users may download and print one copy of any publication from the public portal for the purpose of private study or research.

- You may not further distribute the material or use it for any profit-making activity or commercial gain

- You may freely distribute the URL identifying the publication in the public portal 


\section{Accepted Manuscript}

Life cycle assessment comparing the treatment of surplus activated sludge in a sludge treatment reed bed system with mechanical treatment on centrifuge

Julie D. Larsen, Marieke ten Hoeve, Steen Nielsen, Charlotte Scheutz

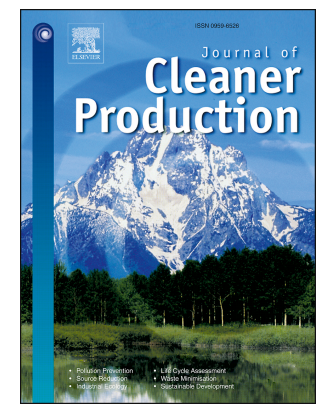

PII:

S0959-6526(18)30512-2

DOI:

10.1016/j.jclepro.2018.02.193

Reference: JCLP 12140

To appear in: Journal of Cleaner Production

Received Date: 12 June 2017

Revised Date: 20 January 2018

Accepted Date: 18 February 2018

Please cite this article as: Larsen JD, Hoeve Mt, Nielsen S, Scheutz C, Life cycle assessment comparing the treatment of surplus activated sludge in a sludge treatment reed bed system with mechanical treatment on centrifuge, Journal of Cleaner Production (2018), doi: 10.1016/j.jclepro.2018.02.193.

This is a PDF file of an unedited manuscript that has been accepted for publication. As a service to our customers we are providing this early version of the manuscript. The manuscript will undergo copyediting, typesetting, and review of the resulting proof before it is published in its final form. Please note that during the production process errors may be discovered which could affect the content, and all legal disclaimers that apply to the journal pertain. 
1 Life cycle assessment comparing the treatment of surplus activated sludge in a sludge treatment reed bed system with mechanical treatment on centrifuge

3

4 Julie D. Larsen ${ }^{\mathrm{ab}}$, Marieke ten Hoeve ${ }^{\mathrm{b}}$, Steen Nielsen ${ }^{\mathrm{a}}$, Charlotte Scheutz ${ }^{\mathrm{b}}$

$5 \quad{ }^{\text {a }}$ Orbicon A/S, DK-4000 Roskilde, Denmark

$6{ }^{\mathrm{b}}$ Department of Environmental Engineering, Technical University of Denmark, DK-2800 Kgs.

7 Lyngby, Denmark

8

9 Corresponding Author:

10 Steen Nielsen

11 Orbicon A/S, DK-4000 Roskilde, Denmark

12 SMNI@orbicon.dk 


\section{Abstract}

In Denmark, the conventional method for treating sewage sludge is mechanical dewatering and subsequent storage. However, sludge treatment reed bed systems, which are holistic sludge treatment facilities combining the dewatering, mineralisation and storage of sludge, have been more common during the last three decades. Treatment of sludge in a sludge treatment reed bed system can be combined with post-treatment (further dewatering and mineralisation) on a stockpile area. This study aimed to compare the environmental performances of a mechanical sludge treatment method with the sludge treatment reed bed system strategy, using the life cycle assessment approach and a life cycle inventory based on newly generated data obtained from Danish reference facilities. The scenarios based on the different treatment methods were initiated by sludge entering the sludge treatment reed bed system or the centrifuge and terminated by land application of the final sludge product. The environmental impacts caused by the sludge treatment reed bed system strategy was comparable to or lower than those caused by the mechanical sludge treatment method. The impacts on climate change were the same for all the treatment scenarios; however, the conversion of organic carbon and nitrogen into gas species was more efficient in the sludge treatment reed bed system compared to mechanical treatment. Thus, mechanically treated sludge contained more nitrogen, causing higher nitrogen emissions (primarily nitrate run-off) when applied on land. According to the results of the life cycle assessment, there were no considerable environmental gains made by adding post-treatment on a stockpile area to the sludge treatment reed bed strategy. However, some practical aspects not included in a life cycle assessment, should also be taken into consideration when evaluating the performances of sludge treatment scenarios.

\section{Keywords:}

Sewage sludge, land application, eutrophication, climate change, environmental impact, nitrogen 


\section{Introduction}

Sludge Treatment Reed Bed (STRB) systems have been used for treating sludge in Denmark since 1988 (Nielsen et al. 2014). The STRB system treatment method is also employed in other European countries, e.g. France (Vincent et al. 2011), Italy (Peruzzi et al. 2013), Spain (Uggetti et al. 2009) and United Kingdom (Nielsen \& Cooper 2011). An STRB system is a holistic sludge treatment facility that combines the dewatering, mineralisation and storage of sludge. These systems are often used for the treatment of sludge originating from domestic wastewater treatment, but they are also used to treat other types of sludge, e.g. from waterworks (Nielsen \& Cooper 2011) or aqua cultural sludge (Summerfelt et al. 1999). Commonly, an STRB system is built as a part of a wastewater treatment plant (WWTP) and receives the sludge produced at this unit. An STRB system consists of a number of beds, often eight to 10 (Nielsen \& Willoughby 2005) or more, to which sludge is applied over several years. While retained in the beds, the sludge is gradually dewatered and mineralised. After 8 to 12 years of dewatering and mineralisation, the final sludge product (the sludge residue left at the end of the entire treatment and storage processes) is excavated and applied to agricultural land as fertiliser and soil improvement.

Since STRB systems were introduced in Denmark, it has been common practice to empty beds during late summer or early autumn and then transport the excavated sludge residue directly to agricultural land after harvest. However, in recent years, a new procedure has been employed by some STRB systems: The beds are emptied in spring and the excavated sludge residue immediately transferred to a stockpile area at the WWTP where it undergoes post-treatment (further dewatering and mineralisation) until autumn. During post-treatment, the sludge residue undergoes further mineralisation and dewatering due to increased evaporation. This approach has the advantage that the emptied beds can be put back into operation in summer, as the reeds will regrow during spring/early summer. If the excavation happens in autumn, the emptied bed must still rest until next 
coming spring/summer, as the reeds remain dormant during autumn and winter. Originally, stockpile areas were of a simple design, namely an outdoor area on which the sludge residue was piled. Recently, coverage of the area by a greenhouse roof and walls has been added to the design, adding a solar drying effect to the post-treatment process.

Conventionally, sewage sludge is dewatered by mechanical devices, such as decanter centrifuges and screw presses, and subsequently stored until it can be applied on agricultural land as fertiliser (Jensen \& Jepsen 2005). Only a few studies assessing the environmental impacts of sludge treatment technologies include STRB systems (Uggetti et al. 2011; Kirkeby et al. 2013) has ben done, as data on STRB systems suited for life cycle assessment (LCA) are scarce. Furthermore, the reliability of the results of these studies could be questioned: A considerable part of the inventory data used by Kirkeby et al. (2013) to model the environmental impacts caused by the STRB system strategy, were not based on actual data from STRB systems but on emission data from crop land or compost windrows. Hence, the results presented in Kirkeby et al. (2013) are somewhat unreliable. The LCA method, data and assumptions used in Uggetti et al. (2011) are somewhat intransparent, making it difficult to compare the outcome of that study with other studies. Only in recent years, new life cycle inventory data on STRB systems, including substance flows in STRB systems (Larsen et al. 2017a), gas emissions from the mineralisation process occurring in STRB systems (Larsen et al. 2017b) and fertiliser quality of sludge residue for land application (Gómez-Muñoz et al. 2017), have been generated. Combined, these studies provide the first datasets on STRB systems made with the purpose of being suitable for LCA; these datasets were not available at the time the mentioned studies by Uggetti et al. (2011) and Kirkeby et al. (2013) were conducted. The aim of the present study was to evaluate the environmental performances of the STRB system strategy using the newest obtained data and according to the international ISO standards for LCA. The performance of the STRB systems strategy was compared to a conventional treatment 
strategy based on centrifugal dewatering of sludge, subsequent storage and final application on agricultural land. To assure that the comparison of the treatment strategies was as up-to-date, new process specific data for the conventional treatment strategy was generated for the purpose. Three sludge treatment scenarios, all of which reflected the management of surplus-activated sludge (SAS) generated at a reference WWTP, were defined and covered treatment, storage, transportation and application of the final sludge product on agricultural land, including the substitution of mineral nitrogen $(\mathrm{N})$, phosphorous $(\mathrm{P})$ and potassium $(\mathrm{K})$ fertiliser, and the treatment of reject water generated during the sludge treatment process.

\section{Materials and methods}

\subsection{The life cycle assessment approach}

An LCA can be applied for comparing resource consumption and impacts on the environment of products or services that provide the same function (ILCD 2010). The LCA in this study complied with ISO 14040 and ISO 14044 standards. In this study, an attributional LCA modelling approach was chosen, and the multi-functionality of processes was dealt with by employing system expansion. LCA modelling was done with the mass flow-based LCA software EASETECH, developed by the Technical University of Denmark and as described in Clavreul et al. (2014). The LCA included three sludge treatment scenarios based on specific case studies of the sludge treatment methods employed at the main reference site, namely a WWTP in Helsinge (Denmark) (56 $\left.01^{\prime} 15 \mathrm{~N} ; 12^{\circ} 19,49 \mathrm{E}\right)$. This WWTP houses an STRB system, a stockpile area and a mechanical sludge treatment device, namely a decanter centrifuge. Data for the life cycle inventory (LCI) were collected at this site and supplemented by data from three other recent studies (GómezMuñoz et al. 2017; Larsen et al. 2017b, 2017a) carried out at Helsinge WWTP and another comparable WWTP, namely Himmark WWTP, (Denmark) (55²'44"N 945'55"E). 
Helsinge WWTP receives domestic wastewater and treats it accordingly, corresponding to 25,000 person equivalents (PE) annually. The wastewater is treated by a mechanical-biological wastewater treatment line. A more detailed description of the wastewater treatment line at Helsinge WWTP is found in the Supplementary Information (SI) (section SI-1).

The STRB system at Helsinge WWTP was established in 1996 (Fig. SI-1a and 1b) and is a representative reference for the present-day STRB system technology. Since 1996, it has been well operated, delivering a final sludge residue of high quality. Table SI-1 provides an overview of the operational data and system characteristics for Helsinge STRB.

The stockpile area at Helsinge WWTP was established in 2012 - 2013 (Fig. SI-1a and 1c) and has a total area of $1,675 \mathrm{~m}^{2}$, with $800 \mathrm{~m}^{2}$ covered by a greenhouse roof, which enhances evaporation from the sludge residue subjected to treatment. Recently, greenhouse walls on two sides have been added to the design.

\subsection{Scope definition}

Three sludge treatment scenarios were analysed: 1) mechanical dewatering by a decanter centrifuge, followed by six months of storage, 2) 12 years of treatment in an STRB system and 3) 12 years of treatment in an STRB system followed by four months of post-treatment at a stockpile area. The scenarios were defined as:

\section{$\underline{\text { Scenario 1: Mechanical treatment (S-CEN) }}$}

Sludge is dewatered on a conventional decanter centrifuge and immediately transferred to a container in which the sludge is stored for one week ("on-site storage"). Afterwards, the dewatered sludge is transported $70 \mathrm{~km}$ by truck to an external sludge storage facility ("external storage"). Here, the dewatered sludge is laid out in layers 1 to $1.5 \mathrm{~m}$ in height on the floor in an enclosed 
storage building. The dewatered sludge is not moved or treated during storage. The storage facility continually receives sludge during the year until autumn, following which it is collected and transferred to a land application site. This procedure implies that at the time of land application, some of the stored sludge has resided at the storage facility for almost one year, while some has only been there for a few days; hence, the average storage time for this study was assumed to be six months. Finally, the dewatered sludge is excavated from the storage facility, transported $200 \mathrm{~km}$ by truck to a land application site and applied by tractor.

\section{$\underline{\text { Scenario 2: Sludge treatment reed bed system (S-STRB) }}$}

Sludge is loaded into an STRB system and undergoes 12 years of treatment (more information on the STRB system technology is provided in SI (section SI-2). The sludge residue (including reeds) is excavated and immediately transported $10 \mathrm{~km}$ by truck to a land application site and applied on land by tractor.

\section{Scenario 3: Sludge treatment reed bed system and stockpile area (S-SPA)}

Sludge is loaded into an STRB system and undergoes 12 years of treatment (the exact same procedure as in S-STRB). The sludge residue (including reeds) is excavated by an excavator and transported $0.15 \mathrm{~km}$ by truck to a stockpile area. The sludge residue is piled and undergoes four months of post-treatment, which is enhanced by solar drying. Finally, the final sludge product is excavated from the stockpile area, transported $10 \mathrm{~km}$ by truck to a land application site and applied by tractor.

The system boundaries included all unit processes (Fig. 1) related to sludge treatment and final land application, including the effect of fertiliser substitution, the treatment of reject water and the treatment of SAS produced from the reject water. The temporal scope for the emission inventory 
and the impact assessment were both defined as 100 years, and the geographical boundary was Denmark. The functional unit (FU) was defined as the treatment and disposal of $1000 \mathrm{~kg}$ wet weight (WW) of SAS with characteristics corresponding to the SAS generated at Helsinge WWTP (Table 1). We decided to base the FU on the WW of the SAS as a central purpose of the treatment processes are dewatering, and thereby volume reduction of the sludge. If based on the dry weight of the sludge, this aspect of the treatment processes would not be reflected in the results of the LCA.

\subsection{Life Cycle Inventory (LCI)}

\subsubsection{Daily operation and transportation}

Data and assumptions on daily operations, excavation and transportation included in the various scenarios were based on the present-day situation and procedures at Helsinge WWTP. All scenarios included consumption of electricity due to pumping of sludge and reject water and the consumption of fuel for excavation and transportation. Furthermore, the centrifuging process included in S-CEN requires an additional input of electricity and that the sludge is pre-conditioned by adding polymer coagulant; hence, emissions related to the production of polymer coagulant were included in this scenario. Data on emissions related to the consumption of electricity and fuel in the different scenarios, and the production of polymer coagulants, were taken from the Ecoinvent v 3.3 database and the database included in the EASETECH software. More details on consumption by the three scenarios are to be found in SI (section SI-3).

For S-CEN, it was assumed that the final sludge product was transported $200 \mathrm{~km}$ to the land application site, while in S-STRB and S-SPA this distance was only $10 \mathrm{~km}$. Sludge residue treated in a well-operated STRB system commonly meets the threshold values for heavy metals and xenobiotics in biosolids for land application, as required by Danish legislation (Nielsen 2005; Miljøministeriet 2017). Furthermore, sludge residue is odourless. Therefore, sludge residue can 
193

194

195

often be applied on agricultural land in the local area. On the other hand, sludge, which has been mechanically dewatered and subsequently stored, often has a strong odour. Even though the dewatered sludge meets the threshold values required by the legislation, the odour makes it difficult to find a land application site willing to take it (information provided by Grib Vand, the utility managing Helsinge WWTP). Therefore, longer transportation distances are often required, as there are fewer local land application sites available to receive the mechanical dewatered sludge.

\subsubsection{Gas emission rates and flow of substances included in S-CEN}

Helsinge WWTP houses a centrifuge that is commonly used to treat SAS from other minor WWTP's. To be able to model S-CEN, in which the SAS from Helsinge WWTP is dewatered on the centrifuge, it was arranged that a batch of SAS was dewatered on the centrifuge, instead of being loaded into the STRB, and samples of SAS, dewatered sludge and reject water from the centrifuging process were collected and characterised. These data were used to calculate the amounts of substances allocated to reject water and dewatered sludge during the dewatering process. Emission rates for carbon dioxide $\left(\mathrm{CO}_{2}\right)$, methane $\left(\mathrm{CH}_{4}\right)$ and nitrous oxide $\left(\mathrm{N}_{2} \mathrm{O}\right)$ representing on-site and external storage were obtained from flux chamber measurements carried out at the on-site storage facility, a container, at Helsinge WWTP. The dewatered sludge was stored in the container at a height of approximately $1.5 \mathrm{~m}$ for 100 days running from October to January. Data on $\mathrm{N}_{2}$ and ammonia $\left(\mathrm{NH}_{3}\right)$ emissions were estimated based on emission data recorded at Helsinge WWTP and data obtained from a study measuring gas emission rates from dewatered sludge piled on an outdoor storage area at a Swedish WWTP (Samuelsson et al. 2018). The

Swedish WWTP has a wastewater treatment line that generates sludge comparable to the SAS generated by Helsinge WWTP and was therefore considered an appropriate reference. Gas emission 
rates, losses of carbon $(\mathrm{C})$ and nitrogen $(\mathrm{N})$ and more information on data sources and calculations can be found in SI (section SI-4).

The evaporation of water during on-site storage was assumed negligible, and during external storage it was estimated by combining our calculated values for losing organic matter and data on the total solids content found in dewatered sludge, before and after 200 days of storage, as published in a publication by the Ministry of Environment and Food of Denmark (Miljø- og Fødevareministeriet (2000). As this publication reports that no water leached from the sludge residue during storage, and the amount of ash remained unchanged, it was assumed that no $\mathrm{P}, \mathrm{K}$ or metals had left the system. More information on data sampling procedures, calculations and the shares of substances allocated to different streams in the treatment process can be found in SI (section SI-4). An overview of the flow of substances in the S-CEN scenario based on an input of sludge corresponding to the FU (1000 kg WW SAS) is also provided in SI (section SI-6, Table SI8).

\subsubsection{Gas emission rates and flow of substances included in S-STRB and S-SPA}

Losses of $\mathrm{C}$ and $\mathrm{N}$ by mineralisation, and the related gas emission rates during 12 years of treatment in the STRB system, were modelled using newly generated data presented by Larsen $e t$ al. (2017b). In this study, gas emission rates $\left(\mathrm{CO}_{2}, \mathrm{CH}_{4}\right.$ and $\left.\mathrm{N}_{2} \mathrm{O}\right)$ from the STRB system in Helsinge, covering all four seasons of the year, were measured by employing static surface flux chambers. Ammonia is produced from $\mathrm{NH}_{4}{ }^{+}$and often constitutes a considerable part of the $\mathrm{N}$ loss from sludge and slurries. However, in STRB systems, $\mathrm{NH}_{4}{ }^{+}$is quickly taken up by the reeds or converted into $\mathrm{NO}_{3}{ }^{-}$through nitrification, thereby preventing the formation of $\mathrm{NH}_{3}$. Therefore, it was assumed that the loss of $\mathrm{N}$ to $\mathrm{NH}_{3}$ in $\mathrm{STRB}$ systems was negligible. Gas emission rates related to the mineralisation process during four months of solar drying on stockpile area were modelled 
based on measured emission rates of $\mathrm{CO}_{2}, \mathrm{CH}_{4}$ and $\mathrm{N}_{2} \mathrm{O}$, also through use of static surface flux chambers. $\mathrm{C}$ and $\mathrm{N}$ losses, gas emission rates and more information on data sources and calculations are to be found in SI (section SI-5).

The amounts of substances partitioned to reject water, final sludge residue, mineralisation and evaporation during 12 years of treatment in an STRB and the four months of solar drying at a stockpile area, were modelled based on the substance flow analysis presented in Larsen et al. (2017a). The substance flow analysis presented in that study was based on another Danish STRB system, namely Himmark STRB system, albeit it was assumed that the study was an appropriate reference for our LCA, as both systems are run in accordance with the operational guidelines and produce comparable sludge residues of high quality. More information on data sampling procedures, calculations and the shares of substances allocated to different streams in the treatment process can be found in SI (section SI-5). An overview of the flow of substances in the S-STRB and S-SPA scenarios based on an input of sludge corresponding to the FU (1000 kg WW SAS) is also provided in SI (section SI-6, Table SI-8).

\subsubsection{Long-term emissions from land application and fertiliser substitution}

Emissions related to land application of the final sludge products were modelled using recently obtained emission data for $\mathrm{N}$ and $\mathrm{C}$. The emission data representing soil application of SAS treated in an STRB system (S-STRB) originate from a lab-scale soil incubation study presented in Gómez-Muñoz et al. (2017). The fate of C and N over a 100-year modelling period was obtained by using the Daisy soil-plant-atmosphere system model (version 5.21). Gaseous emissions of $\mathrm{NH}_{3}$ and $\mathrm{N}_{2} \mathrm{O}$, leaching of $\mathrm{NO}_{3}{ }^{-}$to groundwater and surface water, $\mathrm{N}$-uptake by crops and $\mathrm{C}$ sequestration were estimated. When sludge residues are applied on land, it reduces the need for mineral fertiliser. The environmental savings related to avoiding the production and use of mineral fertilisers were 
included in the LCA. It was assumed that ammonium nitrate substituted mineral $\mathrm{N}$ fertiliser, that single superphosphate substituted $\mathrm{P}$ fertiliser and that potassium chloride substituted $\mathrm{K}$ fertiliser. To obtain similar data representing the treatment of SAS in an STRB system combined with post-treatment on a stockpile area (S-SPA) and dewatering by centrifuge (S-CEN), a similar incubation study, following the exact same procedures as described in Gómez-Muñoz et al. (2017), was conducted. More information on the modelling of emissions related to land application and the savings from fertiliser substitution can be found in SI (section SI-7).

\subsubsection{Reject water treatment}

The reject water generated from the centrifuge in scenario S-CEN or dewatering in an STRB system in scenarios S-STRB and S-SPA was returned to the WWTP and treated along with incoming wastewater, thus producing more SAS. All scenarios included one re-run of the reject water, covering its pumping back to the WWTP, the wastewater treatment process (including related emissions to the atmosphere and aquatic environments), the entire sludge treatment processes for the different scenarios and final land application (including fertiliser substitution).

\subsection{Life cycle impact assessment (LCIA)}

Mid-point impact potentials for 14 normalised impact categories were calculated: Depletion of Fossil Abiotic Resources; Depletion of Reserve-based Abiotic Resources; Climate Change; Marine Eutrophication; Freshwater Eutrophication; Terrestrial Eutrophication; Terrestrial Acidification; Stratospheric Ozone Depletion; Photo Oxidant Formation; Ionising Radiation; Particulate Matter Formation; Human Toxicology - Carcinogenic; Human Toxicology - Noncarcinogenic and Ecotoxicity. The choice of LCIA methods for the different impact categories was made according to recommendations provided by the International Reference Life Cycle Data 
System (ILCD) (ILCD 2010; Hauschild et al. 2013). The normalisation reference was found in (Blok et al. 2013). LCIA methods and normalisation references are shown in SI (section SI-8). The loadings and savings calculated for each impact category are presented in six subprocesses: 1) daily operation (electricity consumption for pumping sludge and reject water, polymer coagulant consumption), 2) biological gas emissions during treatment and storage (gas emissions related to on-site and external storage of centrifuged sludge or mineralisation processes in STRB system and stockpile area), 3) transportation and excavation (fuel consumption for trucks, excavators and tractors), 4) land application (gaseous emissions and leaching of substances related to land application of the final sludge product), 5) fertiliser substitution (the effect of substituting the production and use of mineral fertiliser) and 6) reject water treatment (RWT) (pumping of reject water back to the WWTP, electricity consumption related to treatment, gaseous emissions and leaching related to treatment, the re-running of the produced SAS through the entire sludge treatment process, including land application and fertiliser substitution).

\subsection{Uncertainty analysis}

The robustness of the results was analysed on two levels. First, a contribution analysis was performed to identify substances influencing more than $90 \%$ of the overall environmental impact; the results are shown in Table 2. Second, a sensitivity analysis (SA) was conducted by increasing and decreasing mineralisation rates and transportation distances for all scenarios. SA-1 tested how increasing or decreasing the $\mathrm{C}$ and $\mathrm{N}$ mineralisation rates in all scenarios by $10 \%$ of its original value affected the outcome of the LCA. SA-2 tested how changing the transport distances affected the outcomes of the LCA. SA-1 and SA-2 were carried out separately, meaning that changes made for the mineralisation of $\mathrm{C}$ and $\mathrm{N}$ and for transport did not interfere. 


\section{Results and Discussion}

\subsection{Impact categories}

The results of 11 of the 14 impact categories are shown in Fig. 2. The results of the three impact categories not included in Fig. 2 (Stratospheric Ozone Depletion, Photochemical Oxidant Formation and Ionising Radiation) are shown in SI (section S1-9). The impacts of these categories were low compared to the impact categories shown in Fig. 2, and therefore they will not be discussed further.

\subsubsection{Climate change, eutrophication and acidification}

For the impact category Climate Change, the scenarios provided almost equal net loadings into the environment. The loadings adding to this impact category is due mainly to $\mathrm{CH}_{4}$ and $\mathrm{N}_{2} \mathrm{O}$ emissions from treatment in the STRB system (S-STRB and S-SPA), post-treatment at the stockpile area(S-SPA) and storage of dewatered sludge (S-CEN) (Fig. 2b and Table 2). However, in all scenarios emissions of $\mathrm{CH}_{4}$ and $\mathrm{N}_{2} \mathrm{O}$ from the final sludge products after being applied on land also added considerable to Climate Change; indeed, for S-CEN almost $50 \%$ of the loadings adding to this category was caused by emissions of $\mathrm{CH}_{4}$ and $\mathrm{N}_{2} \mathrm{O}$ related to land application. Methane and $\mathrm{N}_{2} \mathrm{O}$ are strong greenhouse gasses having global warming potentials (GWPs) corresponding to 28 and $265 \mathrm{CO}_{2}$ equivalents, respectively, and therefore important to consider in relation to Climate Change (IPCC 2014).

In all scenarios the treatment processes and the land application processes also emitted $\mathrm{CO}_{2}$ and $\mathrm{N}_{2}$. However, as $\mathrm{N}_{2}$ is not a greenhouse gas and $\mathrm{CO}_{2}$ originating from biological sources, such as wastewater and sludge, is considered short-cycled C (IPCC 2007), these emissions are climateneutral. During the 12-year treatment process in the STRB system in S-STRB and S-SPA, the main share of the mineralised $\mathrm{C}$ and $\mathrm{N}$ was emitted as $\mathrm{CO}_{2}(93 \%)$ and $\mathrm{N}_{2}(94 \%)$, while the remaining 
shares of mineralised $\mathrm{C}(7 \%)$ and $\mathrm{N}(6 \%)$ were emitted as $\mathrm{CH}_{4}$ and $\mathrm{N}_{2} \mathrm{O}$, respectively. On the other hand, during the six months of storage of centrifuged sludge at the on-site and external storage facilities in S-CEN, only $48 \%$ of the $\mathrm{C}$ mineralised and $74 \%$ of the $\mathrm{N}$ mineralised was emitted as climate-neutral $\mathrm{CO}_{2}$ and $\mathrm{N}_{2}$, while the remaining shares of $\mathrm{C}(52 \%)$ and $\mathrm{N}(26 \%)$ were emitted as $\mathrm{CH}_{4}$ and $\mathrm{N}_{2} \mathrm{O}$. The greater production and emission of $\mathrm{CO}_{2}$ and $\mathrm{N}_{2}$ from the STRB system in SSTRB and S-CEN compared to the sludge storage facilities is assigned to the efficient aeration of the sludge residue in the STRB system: Air leak to the sludge residue through rhizomes (hollow out-growths produced by the reeds), movements of stems create cracks in the sludge residue surface through which air enters and the joint reject water pipe and ventilation system embedded in the filter layer provides air to the lower parts of the sludge residue (Nielsen 2003). Aeration enhance aerobic microbial activity, leading to the production of $\mathrm{CO}_{2}$ and $\mathrm{N}_{2}$. At the sludge storage facilities centrifuged sludge was not moved or turned during the storage period. An earlier study found that anaerobic conditions are prone to develop in dewatered sludge stored in a storage facility without being turned (Nielsen, 2005), leading to production of $\mathrm{CH}_{4}$ and $\mathrm{N}_{2} \mathrm{O}$.

Aerobic mineralisation is more effective compared to anaerobic mineralisation in terms of the amount of $\mathrm{C}$ and $\mathrm{N}$ converted into gas species. Hence, the amounts of $\mathrm{C}$ and $\mathrm{N}$ mineralised during treatment in the STRB system were almost twice the amounts mineralised during storage of the centrifuged sludge (Table SI-8), while the emissions to air impacting Climate Change provided by biological gas emissions were almost the same for all three scenarios (Fig. 2). Hence, $\mathrm{C}$ and $\mathrm{N}$ is more efficiently removed from the sludge subjected to treatment in S-STRB and S-SPA compared to the sludge treated in S-CEN, despite of the impacts on Climate Change are equal for all three scenarios.

The amount of $\mathrm{C}$ and $\mathrm{N}$ found in the final sludge product affected the impacts from greenhouse gas emissions related to land application. The slower mineralisation rate during the 
treatment process in S-CEN means that more of the $\mathrm{C}$ and $\mathrm{N}$ was found in the final sludge product, which eventually would be applied on land. Indeed, the greenhouse gas emissions from land application of sludge residue were higher for S-CEN compared to S-STRB and S-SPA (Fig. 2). The share of $\mathrm{N}$ emitted as $\mathrm{N}_{2} \mathrm{O}$ after soil application was approximately $3 \%$ for all three sludge products (SI Table SI-9); however, N content in the centrifuged, final sludge product was greater compared to the sludge residue from the STRB system, leading to a larger contribution to Climate Change from S-CEN compared to S-STRB and S-SPA. For all scenarios, small environmental savings in Climate Change impact category were obtained by substituting mineral fertiliser.

For Marine Eutrophication, all scenarios showed a net loading, mainly caused by $\mathrm{NO}_{3}{ }^{-}$

leaching and run-off from land application (Fig. 2b and Table 2). The impact caused by S-CEN was more than twice the impacts caused by S-STRB and S-SPA. This higher loading in S-CEN was due to the larger $\mathrm{N}$ content in the centrifuged sludge, and higher emission factors for $\mathrm{NO}_{3}{ }^{-}$leaching and run-off.

For Terrestrial Eutrophication, all scenarios showed a net loading, caused primarily by $\mathrm{NH}_{3}$ emissions from the land application process (all scenarios) and by $\mathrm{NO}_{\mathrm{x}}$ and $\mathrm{N}$ from the combustion of fossil fuels (all scenarios, but especially S-CEN) (Fig. 2b and Table 2). Ammonia emissions were highest in S-CEN, as the final sludge produced in this scenario contained more $\mathrm{N}$ and had a larger $\mathrm{NH}_{3}$ emission rate for land application than the final sludge in the other scenarios (S-STRB and SSPA).

The impact category Terrestrial Acidification was affected primarily by $\mathrm{NH}_{3}$ emissions from land application and by $\mathrm{SO}_{\mathrm{x}}$ and $\mathrm{NO}_{\mathrm{x}}$ from the combustion of fossil fuels (Fig. 2b and Table 2). For S-CEN and S-STRB, the overall impacts were small net loadings. For S-SPA, the overall impact was a net saving, as the savings caused by fertiliser substitution exceeded the loadings caused by the other sub-categories. 
For Freshwater Eutrophication, net loadings were seen for all scenarios (Fig. 2b). For S-STRB and S-SPA, these loadings were caused mainly by phosphate $\left(\mathrm{PO}_{4}{ }^{3-}\right)$ leaching from the land application of sludge residues, while for S-CEN the impact potentials caused by $\mathrm{PO}_{4}{ }^{3-}$ leaching from land application and reject water treatment were equal in size (Fig. 2b and Table 2). The concentration of $\mathrm{P}$ in the reject water produced by the centrifuge was 10 times the concentration identified in the reject water produced by the STRB. The P leaching factor from the WWTP was relatively high compared to the leaching factor from land application. Therefore, the impact to Freshwater Eutrophication in S-CEN was higher than in S-STRB and S-SPA.

\subsubsection{Ecotoxicity and human toxicity (non-carcinogenic)}

Among all the impact categories, the most affected were Ecotoxicity and Human Toxicity Non-carcinogenic (Fig. 2a). However, metals diverted to the reject water in S-CEN are eventually also land applied, leading to that the contribution to Human Toxicity - Non-carcinogenic and Ecotoxicity were equal for all scenarios. For both impact categories, all scenarios provided a net loading, caused primarily by the presence of zinc and copper in the final sludge product when applied on land (Table 2). As these impact categories are affected by the same substances, the overall results are the same, except for the magnitude of the values. For both categories, the net loadings were the same for all scenarios. In S-STRB and S-SPA, the loading caused by land application was slightly higher compared to S-CEN, due to the larger amounts of metals transferred to the final sludge product produced in S-STRB and S-SPA (Section SI-6, Table SI-8 in SI). 


\subsubsection{Human toxicity (carcinogenic), resource depletion and particulate matter}

For all scenarios, Human Toxicity - Carcinogenic was affected primarily by the presence of nickel and lead in the final sludge product when applied on land (Fig. 2c and Table 2). Small savings were provided by fertiliser substitution. As for Human Toxicity - Non-carcinogenic and Ecotoxicity, the overall impacts were similar for all scenarios.

The impact of Depletion of Fossil Abiotic Resources (Fig. 2c) was higher for S-CEN than for the other two scenarios (S-STRB and S-SPA), due to larger fossil fuel demand related to daily operation, transportation and excavation in this scenario. The main impacts were caused by the consumption of hard coal and crude oil, while the main impacts in S-STRB and S-SPA arose solely from the consumption of hard coal (Table 2). For S-STRB and S-SPA, the overall results were small net savings, as savings from the substitution of mineral fertiliser exceeded loadings. For SCEN, daily operations included the production and consumption of polymer coagulant required for pre-conditioning the sludge prior to centrifuging. The production of this polymer coagulant caused the consumption of crude oil and the higher environmental loading. Furthermore, the transport distances, earlier addressed in section 2.3.1, included in S-CEN were $70 \mathrm{~km}$ from the WWTP to the external storage facility, followed by $200 \mathrm{~km}$ to the land application site, compared to $0.150 \mathrm{~km}$ from the STRB system to the stockpile area in S-SPA, and $10 \mathrm{~km}$ to the land application sites in SSTRB and S-SPA, resulting in a considerably greater demand for fuel in S-CEN.

For the impact category Depletion of Reserve-based Abiotic Resources, all scenarios showed net savings, as the resource consumption avoided from the substitution of mineral fertiliser exceeded the resources needed for sludge management. In S-STRB and S-SPA, positive loadings were negligible compared to savings. For S-CEN, loading was caused mainly by the consumption of lead in relation to the consumption of crude oil. For S-CEN, savings as a result of fertiliser substitution were slightly greater compared to S-STRB and S-SPA, as more mineral fertiliser was 
assumed to be replaced in this scenario. However, due to the larger loading in S-CEN, this scenario provided a lower net saving compared to the other scenarios.

For Particulate Matter, all scenarios showed net savings, due to the substitution of mineral fertiliser. Positive contributions arose mainly from emissions of $\mathrm{NH}_{3}$ and sulphur dioxide $\left(\mathrm{SO}_{2}\right)$ related to the combustion of fuel, and $\mathrm{NH}_{3}$ emissions from land application.

\subsection{Sensitivity analysis}

\subsubsection{Mineralisation rates}

In SA-1, the mineralisation rates for $\mathrm{C}$ and $\mathrm{N}$ mineralised were increased and decreased by $10 \%$ of their original values in all three treatment scenarios (Fig. 3). Changes in the mineralisation rates during the treatment of sludge in the STRB system, in the stockpile area or while storing mechanical dewatered sludge at the external storage facilities affected the impact category Climate Change, as $\mathrm{CH}_{4}$ and $\mathrm{N}_{2} \mathrm{O}$ emissions were affected (Fig. 3). Furthermore, changing the mineralisation rates affected Marine Eutrophication, as the amount of $\mathrm{N}$ found in the final sludge product from the various scenarios depended on the amount of $\mathrm{N}$ mineralised earlier in the treatment process. The effects of SA-1 on the remaining impact categories can be found in SI (section SI-10).

For Climate Change, S-CEN was more affected by changes in the mineralisation rates than the other two scenarios (S-STBR and S-SPA) (Fig. 3). The reason for this was that a larger share of the $\mathrm{C}$ and $\mathrm{N}$ mineralised in $\mathrm{S}-\mathrm{CEN}$ was emitted as $\mathrm{CH}_{4}$ and $\mathrm{N}_{2} \mathrm{O}$ than in the other two scenarios (Table SI-4 in section SI-4 and Table SI-6 in section SI-5 in SI). When the mineralisation rates for $\mathrm{C}$ and $\mathrm{N}$ were decreased by $10 \%$ of their original values for all scenarios, S-CEN showed a lower Climate Change impact than the other scenarios, while it was higher in the default scenario and when mineralisation rates were increased by $10 \%$ (Fig. 3). 
Changing the mineralisation rates for $\mathrm{C}$ and $\mathrm{N}$ had only a small effect on the impact of Marine

Eutrophication in the S-CEN (Fig. 3). Due to a much higher mineralisation rate in the STRB system than while storing centrifuged sludge, S-STRB and S-SPA showed changes in Marine Eutrophication. With a $10 \%$ higher mineralisation rate, less $\mathrm{N}$ remained in the sludge product, leading to a lower impact on Marine Eutrophication, while with a $10 \%$ lower mineralisation rate, more $\mathrm{N}$ remained in the sludge product, leading to a higher Marine Eutrophication impact. However, regardless of the mineralisation rate applied, the impact on Marine Eutrophication impact caused by S-CEN was always more than twice as high compared to S-STRB and S-SPA.

The results of SA-1 reflect a trade-off between the impact on Climate Change and on Marine Eutrophication for the mineralisation rates of $\mathrm{C}$ and $\mathrm{N}$ during treatment or storage. Higher mineralisation rates led to a higher Climate Change impact for S-CEN, but a lower Marine Eutrophication impact for S-STRB and S-SPA, while lower mineralisation rates had the opposite effect.

\subsubsection{Transport distances}

In SA-2, transport distances in the various scenarios were changed. The total transport distances included in the various scenarios were $270 \mathrm{~km}$ for S-CEN, $10 \mathrm{~km}$ for S-STRB and 10.15 $\mathrm{km}$ for S-SPA. First the transport distances were halved for all the scenarios. Second, the transport distance included in S-CEN was reduced to $10.15 \mathrm{~km}$, to match the transportation distance in the other scenarios. The impact category mainly affected by these changes was Depletion of Fossil Abiotic Resources. The effects of SA-2 on the impact category Depletion of Fossil Abiotic Resources are shown in Fig. 3, while the effects on the remaining impact categories can be found in section SI-10 in SI. 
For S-STRB and S-SPA, halving the transport distances did not affect the net impact on Depletion of Fossil Abiotic Resources (Fig. 3), while the net impact for S-CEN was reduced by almost 50\%. However, despite this reduction, the impact potential of S-CEN remained higher than for the other scenarios. Reducing the transportation for S-CEN so it equalled the transportation distance in STRB and S-SPA drastically decreased the impact on Depletion of Fossil Abiotic Resources for S-CEN, though it remained greater than in the other two scenarios, due to a high contribution from producing polymer coagulant.

\subsection{Discussion}

The results of the LCA revealed that in terms of eutrophication of marine environments, the treatment scenarios based on the STRB system strategy (S-STRB and S-SPA) caused lower impacts compared to the conventional strategy using mechanical dewatering on centrifuge (S-CEN). This difference between the treatment strategies are mainly due to that treatment in STRB systems provides a fuller mineralisation of $\mathrm{C}$ - and $\mathrm{N}$-containing compounds, without causing a higher emission of greenhouse gasses. This means that none of the strategies are more favourable when considering impacts on climate change; however, the STRB system strategy is favourable in terms of avoiding eutrophication of marine environments in costal zones. Eutrophication of costal zones due to nutrient run-off from agricultural land has during the last decades been a major problem in Denmark, meaning that this difference between the strategies is highly relevant in Denmark and other countries with similar environmental problems.

The LCA study presented in Kirkeby et al. 2013 also found that eutrophication caused by Ncontaining compounds was higher for sludge treated by a conventional strategy based on mechanical dewatering and subsequent storage compared to sludge treated in an STRB system. However, due to a lack of data for the STRB system strategy at the time Kirkeby et al. (2013) 
conducted their study it difficult to make valid conclusions based a comparing those results to those of our study.

Uggetti et al. (2011), a Spanish study comparing the treatment of sludge in a STRB system with dewatering on centrifuge, did not include emissions of $\mathrm{N}_{2} \mathrm{O}$ from the STRB systems, while the results of our study show that emissions of $\mathrm{N}_{2} \mathrm{O}$ from mineralisation processes are highly relevant to include for both the STRB system method and the mechanical treatment method. Furthermore, Uggetti et al. (2011) did not include final disposal (land application), as the emissions related to this step were expected to be the same for all scenarios. The results of our LCA suggests that this is not true but that emissions related to land application are highly relevant when comparing the environmental performances of sludge treatment methods.

Toxic impacts due to heavy metals were found to be the same for all three treatment scenarios. However, the effect of xenobiotics present in the final sludge products were not included in the impact categories addressed in this LCA. The contents of nonylphenol ethoxylates (NPE), di(2-ethylhexyl)phthalate (DEHP), linear alkylbenzene sulfonates (LAS) and polycyclic aromatic hydrocarbons (PAHs) in sludge products for land application are of concern if the threshold values for these compounds, defined by the Danish Ministry of Environment and Food (Miljøministeriet 2006), are not met. Hence, the flow of xenobiotics in the treatment scenarios would be a relevant topic for future studies.

Overall, the environmental impacts of S-STRB and S-SPA are almost the same. However, adding post-treatment on to stockpile area to the STRB system strategy has some practical advantages that are not expressed in the results of the LCA. The presence of a stockpile area makes it possible to empty STRB system beds in spring, thereby allowing the reeds in the excavated bed to regrow within a few months, compared to almost one year if excavation happens in autumn. Faster regrowth of the reeds implies that the bed can be reintroduced faster into the loading cycle with a 
full loading programme, which enhances the treatment capacity of the STRB system. The stockpile area also provides more flexibility in terms of time for excavating and collecting the final sludge product by the recipient.

\section{Conclusions}

The environmental impacts caused by the sludge treatment scenarios based on the STBR system strategy performed comparable or better compared to the scenario representing a conventional sludge treatment strategy including mechanical dewatering on a centrifuge and subsequent storage. Carbon and nitrogen was more efficiently removed by the treatment processes included in S-STRB and S-SPA, resulting in a lower content of C and $\mathrm{N}$ in the final sludge product compared to S-CEN, despite of the impacts on Climate Change caused by gas emissions from the treatment process were equal for all scenarios. The lower content of $\mathrm{C}$ and $\mathrm{N}$ in the final sludge product produced by S-STRB and S-SPA resulted in considerable lower impacts on Marine Eutrophication compared to S-CEN. A sensitivity analysis revealed that the performances of SSTRB and S-SPA were more robust to changes in the amounts of $\mathrm{C}$ and $\mathrm{N}$ mineralised during the treatment process and changes in transport distances compared to S-CEN. In terms of human toxicity and ecotoxicity, the impacts for all three treatment scenarios were comparable. According to the results of the LCA, there were no considerable differences in the performances of S-STRB and S-SPA. However, adding a stockpile area to the STRB system strategy had some practical advantages, which should be considered.

\section{Acknowledgements}

The work presented herein was funded by an industrial $\mathrm{PhD}$ project hosted by Orbicon $\mathrm{A} / \mathrm{S}$ and The Technical University of Denmark (DTU). The PhD project was funded by the Innovation 
551 Fund Denmark (Project ref. no.: 15146). The authors would like to thank Grib Vand A/S and staff 552 members at Helsinge WWTP for providing operational data and allowing us to carry out 553 experimental work at their facilities.

\section{References}

556 ISO 14040 (2006): Environmental management - Life cycle assessmnet - Principles and framework. International Organisation for Standardisation (ISO), Geneva, Switzerland.

ISO 14044 (2006): Environmental management - Water footprint - Principles, requirements and guidelines Management environnement. International Organisation for Standardisation (ISO), Geneva, Switzerland.

Blok K., Huijbregts M., Patel M., Hertwich E., Hauschild M., Sellke P., Antunes P., Hellweg S., Mays C. and Ciroth A. (2013). Handbook on a Novel Methodology for the Sustainability Impact of New Technologies. Utrecht University Repository.

Clavreul J., Baumeister H., Christensen T. H. and Damgaard A. (2014). An environmental assessment system for environmental technologies. Environ. Model. Softw. 60, 18 - 30.

Gómez-Muñoz B., Larsen J. D., Bekiaris G., Scheutz C., Bruun S., Nielsen S. and Jensen L. S. (2017). Nitrogen mineralisation and greenhouse gas emission from the soil application of sludge from reed bed mineralisation systems. Journal of Environmental Management 203(1), 59-67

Hauschild M. Z., Goedkoop M., Guinée J., Heijungs R., Huijbregts M., Jolliet O., Margni M., De Schryver A., Humbert S. and Laurent A. (2013). Identifying best existing practice for characterization modeling in life cycle impact assessment. The international journal of life cycle assessment 18(3), 683-97. 
ILCD H. (2010). General guide for Life Cycle Assessment - Detailed guidance. Publication Office of the European Union, Luxembourg. doi 10(38479), 0.

IPCC (2007). Climate Change 2007: The Physical Science Basis. Contribution of Working Group I to the Fourth Assessment Report of the Intergovernmental Panel on Climate Change, Cambridge University Press N, USA, Cambridge,United Kingdom and New York.

IPCC (2014). Climate Change 2013: The physical science basis: Working group I contribution to the fifth assessment report of the Intergovernmental Panel on Climate Change. Cambridge University Press.

Jensen J. and Jepsen S. E. (2005). The production, use and quality of sewage sludge in Denmark. Waste Management 25(3), 239-47.

Kirkeby J., Rosenhagen C., Høibye L., Dalgaard O. G., Neidel T. L., Kromann M., Hansen J. P. and Bruun S. (2013). Livscyklusvurdering og samfundsøkonomisk analyse for anvendelse af spildevandsslam, Report Miljøprojekt nr. 1459, Miljøstyrelsen, København.

Larsen J. D., Nielsen S. and Scheutz C. (2017a). Assessment of a sludge treatment reed bed system and a stockpile area, using substance flow analysis Water Science \& Technology (online). DOI: $10.2166 /$ wst.2017.348

Larsen J. D., Nielsen S. and Scheutz C. (2017b). Greenhouse gas emissions from the mineralisation process in a Sludge Treatment Reed Bed system: seasonal variation and environmental impact. Ecological Engeneering 106, 279-286.

Miljø- og Fødevareministeriet M. (2000). Undersøgelses- og moniteringsprogram for omsætningen af miljøfremmedestoffer i slammineraliseringsanlæg og slamlager.

Miljøministeriet (2017). Bekendtgørelse om anvendelse af affald til jordbrugsformål (Slambekendtgørelsen). BEK nr 843 af 23/06/2017 
Nielsen S., Peruzzi E., Macci C., Doni S. and Masciandaro G. (2014). Stabilisation And Mineralisation Of Sludge In Reed Bed System After 10 - 20 Years Of Operation. Water Science \& Technology 69(3), 8.

Nielsen S. and Cooper D. J. (2011). Dewatering sludge originating in water treatment works in reed bed systems. Water Science and Technology 64(2), 361-6.

Nielsen S. and Willoughby N. (2005). Sludge treatment and drying reed bed systems in Denmark. Water and Environment Journal 19(4), 296-305.

Nielsen S. (2005). Mineralisation of hazardous organic compounds in a sludge reed bed and sludge storage. Water Science and Technology 51(9), 109-17.

Nielsen S. (2003). Sludge drying reed beds. Water Science and Technology 48(5), 101-9.

Peruzzi E., Nielsen S., Macci C., Doni S., Iannelli R., Chiarugi M. and Masciandaro G. (2013). Organic matter stabilization in reed bed systems: Danish and Italian examples. Water Science \& Technology 68(8), 1888-94.

Samuelsson J., Delre D., Tumlin S., Hadi S., Offerle B. and Scheutz C. (2018). Optical technologies applied with on-site and remote methods for air emission quantifications from a wastewater treatment plant. Water Reseach. 131(15), 299-309.

Summerfelt S. T., Adler P. R., Glenn M. and Kretschmann R. N. (1999). Aquaculture sludge removal and stabilization within created wetlands. Aquacultural Engineering 19, 81-92.

Uggetti E., Ferrer I., Molist J. and Garcia J. (2011). Technical, economic and environmental assessment of sludge treatment wetlands. Water Reseach 45(2), 573-82.

Uggetti E., Llorens E., Pedescoll A., Ferrer I., Castellnou R. and Garcia J. (2009). Sludge dewatering and stabilization in drying reed beds: characterization of three full-scale systems in Catalonia, Spain. Bioresource Technology 100(17), 3882-90. 
620 Vincent J., Molle P., Wisniewski C. and Lienard A. (2011). Sludge drying reed beds for septage 621 treatment: Towards design and operation recommendations. Bioresource Technology 102(17),

622 8327-30.

623 
Table 1. Quality of the surplus-activated sludge produced at the Helsinge wastewater treatment plant (WWTP).

\section{Wastewater treatment at Helsinge WWTP}

\begin{tabular}{|c|c|c|c|}
\hline Sludge type & & Surplus-activate & SAS) \\
\hline Sludge age (aerobic days) & & $20-25$ & \\
\hline Phosphorous removal & & PIX & \\
\hline Cha & cterisation of : & d sludge (SAS) & \\
\hline Parameter & & Parameter & \\
\hline Total solid (TS) (\% of WW) & 0.6790 & $\mathrm{Cr}(\%$ of $\mathrm{DW})$ & 0.0023 \\
\hline Volatile solid (VS) (\% of DW) & 61.483 & $\mathrm{Mn}(\%$ of $\mathrm{DW})$ & 0.0747 \\
\hline Total nitrogen $(\mathrm{TN})(\%$ of $\mathrm{DW})$ & 3.9700 & $\mathrm{Fe}(\%$ of $\mathrm{DW})$ & 6.3970 \\
\hline Total carbon (TC) (\% of DW) & 27.890 & $\mathrm{Ni}(\%$ of DW) & 0.0022 \\
\hline $\mathrm{NO}_{3}^{-}-\mathrm{N}(\%$ of $\mathrm{DW})$ & 0.000015153 & $\mathrm{Cu}(\%$ of DW $)$ & 0.0314 \\
\hline $\mathrm{NH}_{4}{ }^{+}-\mathrm{N}(\%$ of DW $)$ & 0.000000001 & $\mathrm{Zn}(\%$ of $\mathrm{DW})$ & 0.0573 \\
\hline $\mathrm{Mg}(\%$ of DW $)$ & 0.4234 & $\mathrm{Cd}(\%$ of DW $)$ & 0.0001 \\
\hline $\mathrm{P}(\%$ of $\mathrm{DW})$ & 2.2900 & $\mathrm{~Pb}(\%$ of $\mathrm{DW})$ & 0.0030 \\
\hline $\mathrm{Ca}(\%$ of $\mathrm{DW})$ & 2.8255 & $\mathrm{~K}(\%$ of $\mathrm{DW})$ & 0.3911 \\
\hline
\end{tabular}

WW: wet weight, DW: dry weight 
Table 2. Compounds responsible for $>90 \%$ of the total impact in 11 impact categories for the three scenarios. The compounds vary among the following six life cycle stages: daily operation, biological gas emissions, transportation/excavation, land application, fertiliser substitution and reject water treatment (RWT).

\begin{tabular}{|c|c|c|c|}
\hline Impact Category & S-CEN & S-STRB & S-SPA \\
\hline Climate change & $\mathrm{CH}_{4}, \mathrm{~N}_{2} \mathrm{O}$ & $\mathrm{CH}_{4}, \mathrm{~N}_{2} \mathrm{O}$ & $\mathrm{CH}_{4}, \mathrm{~N}_{2} \mathrm{O}$ \\
\hline $\begin{array}{l}\text { Freshwater } \\
\text { eutrophication }\end{array}$ & $\mathrm{PO}_{4}^{3-}, \mathrm{P}$ & $\mathrm{PO}_{4}^{3-}, \mathrm{P}$ & $\mathrm{PO}_{4}^{3-}, \mathrm{P}$ \\
\hline Marine eutrophication & $\mathrm{NO}_{3}^{-}$ & $\mathrm{NO}_{3}^{-}$ & $\mathrm{NO}_{3}^{-}$ \\
\hline Terrestrial acidification & $\mathrm{NH}_{3}, \mathrm{SO}_{\mathrm{x}}, \mathrm{NO}_{\mathrm{x}}$ & $\mathrm{NH}_{3}, \mathrm{SO}_{\mathrm{x}}, \mathrm{NO}_{\mathrm{x}}$ & $\mathrm{NH}_{3}, \mathrm{SO}_{\mathrm{x}}, \mathrm{NO}_{\mathrm{x}}$ \\
\hline $\begin{array}{l}\text { Terrestrial } \\
\text { eutrophication }\end{array}$ & $\mathrm{NH}_{3}, \mathrm{NO}_{\mathrm{x}}$ & $\mathrm{NH}_{3}, \mathrm{NO}_{\mathrm{x}}$ & $\mathrm{NH}_{3}, \mathrm{NO}_{\mathrm{x}}$ \\
\hline $\begin{array}{l}\text { Human toxicity - non- } \\
\text { carcinogenic }\end{array}$ & $\mathrm{Zn}$ & $\mathrm{Zn}$ & $\mathrm{Zn}$ \\
\hline Ecotoxicity & $\mathrm{Zn}, \mathrm{Cu}$ & $\mathrm{Zn}, \mathrm{Cu}$ & $\mathrm{Zn}, \mathrm{Cu}$ \\
\hline $\begin{array}{l}\text { Human toxicity - } \\
\text { carcinogenic }\end{array}$ & $\mathrm{Ni}$ & $\mathrm{Ni}$ & $\mathrm{Ni}$ \\
\hline $\begin{array}{l}\text { Depletion of fossil } \\
\text { abiotic resources }\end{array}$ & $\begin{array}{l}\text { Hard coal, crude } \\
\text { oil }\end{array}$ & Hard coal & Hard coal \\
\hline $\begin{array}{l}\text { Depletion of reserve- } \\
\text { based abiotic resources }\end{array}$ & $\mathrm{In}, \mathrm{Cd}$ & In, $\mathrm{Cd}$ & In, $\mathrm{Cd}$ \\
\hline Particulate matter & $\mathrm{NH}_{3}, \mathrm{SO}_{2}$ & $\mathrm{NH}_{3}, \mathrm{SO}_{2}$ & $\mathrm{NH}_{3}, \mathrm{SO}_{2}$ \\
\hline $\begin{array}{l}\text { Photochemical oxidant } \\
\text { formation }\end{array}$ & $\begin{array}{c}\mathrm{NO}_{\mathrm{x}} \\
\mathrm{NMVOC}\end{array}$ & $\begin{array}{l}\mathrm{NO}_{\mathrm{x}} \\
\mathrm{SO}_{2}\end{array}$ & $\begin{array}{l}\mathrm{NO}_{\mathrm{x}} \\
\mathrm{SO}_{2}\end{array}$ \\
\hline $\begin{array}{l}\text { Stratospheric ozone } \\
\text { depletion }\end{array}$ & $\begin{array}{c}\text { CFC-11, CFC-13, } \\
\text { HCFC-12 }\end{array}$ & CFC-11 & CFC-11 \\
\hline
\end{tabular}


[Type text]

\begin{tabular}{|c|c|c|c|c|c|c|c|c|}
\hline \multirow{2}{*}{ S - CEN } & SAS & 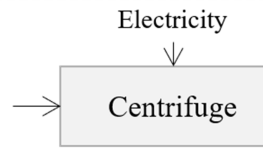 & $\begin{array}{l}\text { On-site storage } \\
\text { (1 week) }\end{array}$ & $\begin{array}{c}\text { Fuel } \\
\vee \\
\text { Transport }\end{array}$ & $\begin{array}{l}\text { External storage } \\
\quad(6 \text { months })\end{array}$ & $\begin{array}{c}\text { Fuel } \\
\vee \\
\text { Excavation/ } \\
\text { Transport }\end{array}$ & 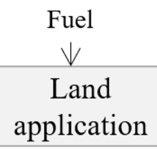 & $\begin{array}{l}\text { Fertilizer } \\
\text { substitution }\end{array}$ \\
\hline & Electricity & $\longrightarrow \begin{array}{c}\text { Reject water } \\
\text { treatment }\end{array}$ & & & & & & \\
\hline \multirow{3}{*}{ S - STRB } & & $\begin{array}{c}\text { Electricity } \\
\vee\end{array}$ & & & & $\begin{array}{c}\text { Fuel } \\
\vee\end{array}$ & Fuel & \\
\hline & & $\rightarrow \begin{array}{c}\text { STRB system } \\
\text { (12 years })\end{array}$ & & & & $\begin{array}{c}\text { Excavation/ } \\
\text { Transport }\end{array}$ & $\begin{array}{c}\text { Land } \\
\text { application }\end{array}$ & $\begin{array}{c}\text { Fertilizer } \\
\text { substitution }\end{array}$ \\
\hline & Electricity & $\longrightarrow \begin{array}{c}\text { Reject water } \\
\text { treatment }\end{array}$ & & & & & & \\
\hline \multirow{3}{*}{ S-SPA } & & $\begin{array}{c}\text { Electricity } \\
\vee\end{array}$ & & $\begin{array}{l}\text { Fuel } \\
\vee\end{array}$ & & $\begin{array}{l}\text { Fuel } \\
\vee\end{array}$ & $\begin{array}{l}\text { Fuel } \\
\vee\end{array}$ & \\
\hline & SAS & Centrifuge & & $\begin{array}{c}\text { Excavation/ } \\
\text { Transport }\end{array}$ & $\begin{array}{l}\text { Stockpile area } \\
\text { (4 months) }\end{array}$ & $\begin{array}{c}\text { Excavation/ } \\
\text { Transport }\end{array}$ & $\begin{array}{c}\text { Land } \\
\text { application }\end{array}$ & $\begin{array}{c}\text { Fertilizer } \\
\text { substitution }\end{array}$ \\
\hline & Electricity & $\longrightarrow \begin{array}{c}\text { Reject water } \\
\text { treatment }\end{array}$ & & & & & & \\
\hline
\end{tabular}

Fig. 1. Unit processes for three sludge treatment scenarios: Scenario S-CEN (dewatering on a centrifuge, one week of on-site storage and 6 months' external storage until land application), Scenario S-STRB (12 years of treatment in an STRB system, excavation in autumn and immediate application on land) and Scenario S-SPA (12 years of treatment in an STRB system, excavation in spring, four months' solar drying at an SPA and, finally, application on land during the following autumn). 

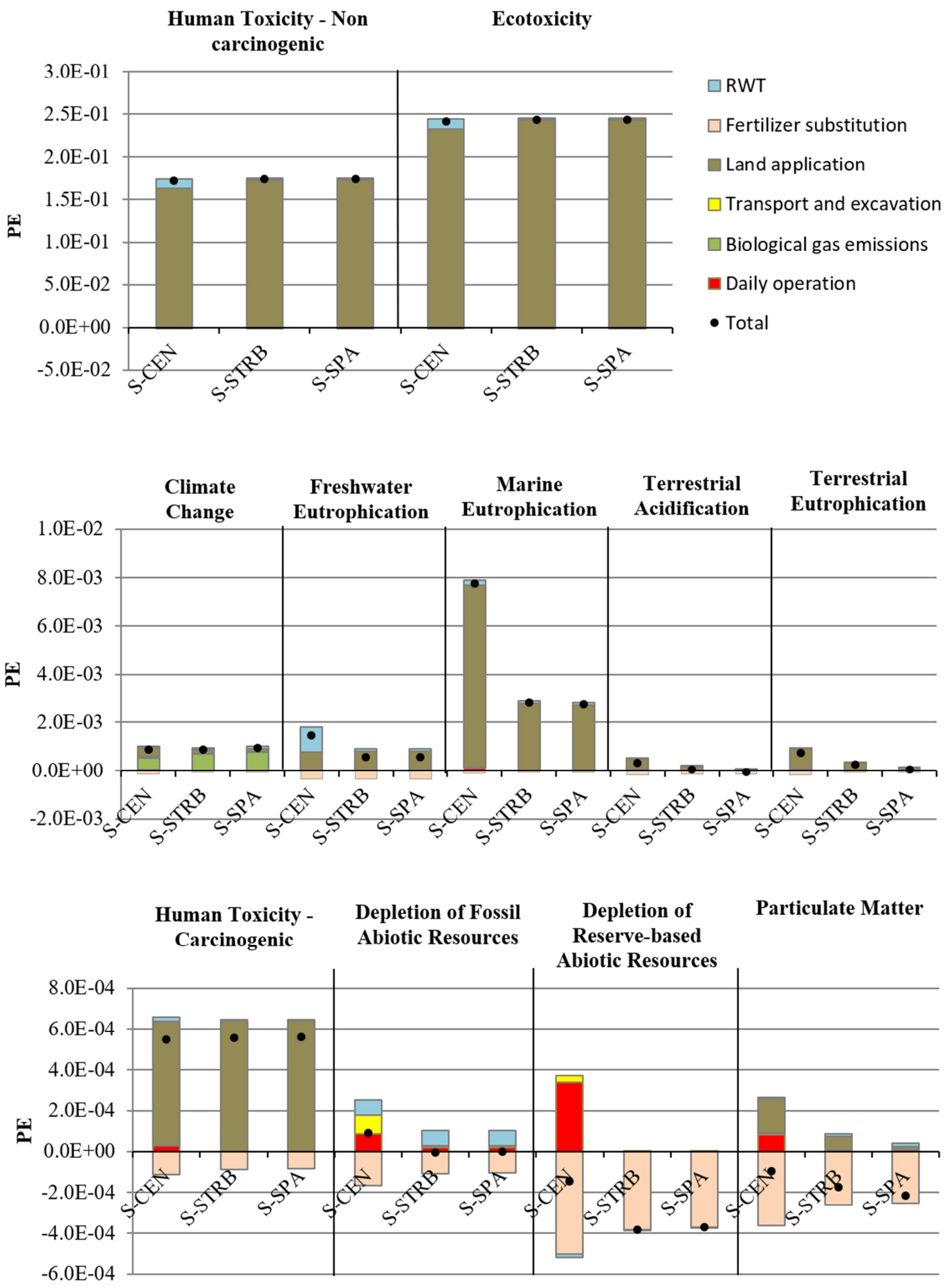

Fig. 2. Life cycle impact assessment of 11 impact categories for three treatment scenarios: 1) dewatering on a centrifuge (S-CEN), 2) 12 years of treatment in STRB (S-STRB) and 3) 12 years of treatment in STRB, followed by four months of post-treatment in a stockpile area covered by a greenhouse roof (S-SPA). 

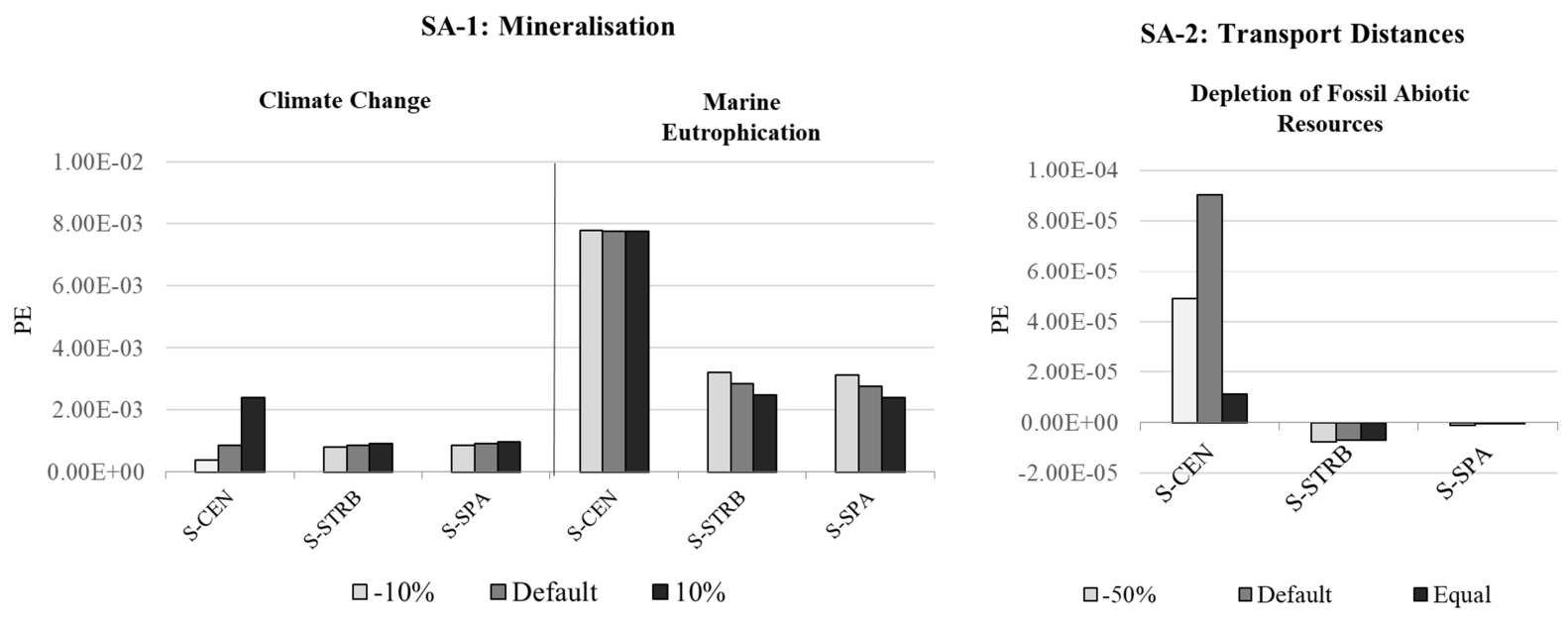

Fig. 3. Results of the sensitivity analysis (SA) testing the robustness of the results in relation to mineralisation rate (SA-1) and transport distances (SA-2) in the treatment scenarios S-CEN, SSTRB and S-SPA. "Default" bars represent total impacts caused by the different scenarios in the LCA modelling. For SA-1, “-10\%" and "+10\%" represent changes in the impact categories "Climate Change" and "Marine Eutrophication" from the different scenarios, if the amounts of mineralised $\mathrm{C}$ and $\mathrm{N}$ are decreased or increased by $10 \%$. For SA-2, “-50\%" represents the impacts to "Depletion of Fossil Abiotic Resources", if the transport distances in all scenarios are reduced by 50\%. "Equal" represents impacts caused if the transport distances in all scenarios are set to $10 \mathrm{~km}$. 


\section{Highlights:}

2 - A life cycle assessment comparing sludge treatment scenarios was performed

3 - The assessment focused on environmental impacts related to 14 impact categories

4 - One scenario was based on mechanical dewatering, two on treatment in reed beds

5 - Newly generated process specific inventory data was used to model the scenarios

6 - Overall, the treatment in reed beds performed better than mechanical dewatering 